\title{
COMMUNICATIONS
}

\section{PHOTOELECTRIC METHOD OF INVESTIGATING THE AMOUNT AND OXYGENATION OF BLOOD IN THE FUNDUS OCULI*}

\author{
BY \\ K. D. BROADFOOT, J. GLOSTER, AND D. P. GREAVES \\ Institute of Ophthalmology, University of London. Director of Research- \\ Sir Stewart Duke-Elder
}

THE serious loss of vision which commonly follows a rise in intra-ocular pressure is a familiar clinical experience, but the characteristics of the rate or type of visual loss are not necessarily proportional to the degree of rise in pressure, nor to the length of time for which it operates. Since it is impossible to predict precisely the amount or rate of visual loss from the degree of elevation of the intra-ocular pressure, it is reasonable to postulate that some other factor or factors determine the vulnerability of the nervous elements of the eye to a pathological rise in pressure.

In general, body tissues, especially nervous cells, depend on an adequate blood supply for normal functioning, and it may be that modification of the circulation of blood within the eye by a rise in intra-ocular pressure plays a part in determining the loss of visual function in glaucoma. With these ideas in mind we have attempted to devise a method for studying certain aspects of the vascular circulation inside the eye.

Schubert (1936), using diascleral illumination in albino rabbits, was able to demonstrate photoelectrically that the amount of light leaving the eye through the pupil changed during asphyxia, carotid occlusion, and exsanguination; the technique necessitated subluxating the globe in front of the eyelids. More recently Niedermeier (1958) claimed to have measured the thickness of the choroid by photographic measurement of the amount of light emerging from the pupil during diascleral illumination with yellowgreen light. We thought it would be preferable to employ the principle used for the study of visual pigments (Weale, 1953; Rushton, 1956), in which the fundus is illuminated through the pupil and the amount of light returning through it is measured.

Our requirements were that the method should indicate $(a)$ changes in the amount of blood in the choroid and $(b)$ alterations in the colour of the blood, particularly those induced by changes in oxygen saturation or by the intravenous injection of dyes. Alterations in the amount of blood in the 
choroid are best studied by illuminating the eye with green light, and variations in colour due to changes in oxygen saturation can be followed by using red light as in the standard methods of oximetry (Zijlstra, 1958). When coloured substances are injected into the blood stream, it is necessary to employ light of a colour complementary to that of the dye.

Our apparatus was designed so that lights of three different colours were projected into the eye in continuous and rapid succession; the light returning from the eye fell on to the cathode of a photomultiplier. By means of a suitable electronic arrangement it was thus possible to obtain practically simultaneous records of the amount of each coloured light reflected from the fundus.

The scope of this paper is restricted to a description of the apparatus and the presentation of results which demonstrate that the technique can be used to follow changes in the amount of blood in the choroid and alterations in its oxygen saturation.

\section{Apparatus}

A small Gullstrand ophthalmoscope was modified as shown diagrammatically in Fig. 1. The light source was a straight-filament 12 v. 12 w. bulb supplied by a Servomex voltage stabilizer (Type DC 65). A rotating disc $17.5 \mathrm{~cm}$. in diameter was interposed in the beam of light immediately in front of the large condenser prism of the ophthalmoscope. The disc was attached to the spindle of a small electric motor driven at 2,500 r.p.m. by a second Servomex voltage stabilizer. The colour filters were situated in three apertures $(3.8 \mathrm{~cm}$. in diameter) in the disc, which were equidistant from one another and with centres $5.5 \mathrm{~cm}$. from the centre of rotation of the disc. Three smaller apertures $(1.5 \mathrm{~mm}$.) placed near the periphery of the disc were used in conjunction with a small light source and a photodiode to operate electronic switch-gear linked with the output of a photomultiplier (E.M.I. 9528B) which replaced the viewing eyepiece. Two polaroid

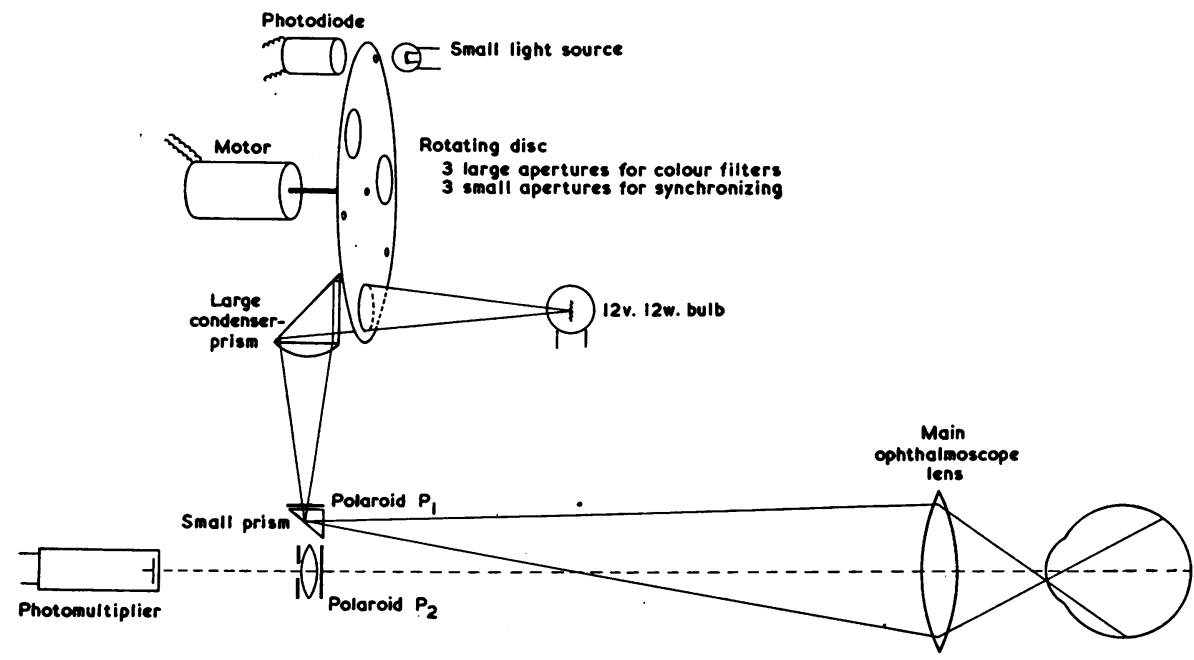

FIG. 1.-Basic diagram of optical system employed in apparatus. 
filters were interposed in the light path; one $\left(\mathrm{P}_{1}\right)$ was in the incident beam of light above the small prism, and the other $\left(\mathrm{P}_{2}\right)$, with its plane of polarization at rightangles to the former, was in front of the photomultiplier. This combination was found necessary to eliminate unwanted light returning by specular reflection from the surfaces of the main ophthalmoscope lens.

It is appropriate at this stage to discuss our choice of colour filters. Although on theoretical grounds it would have been desirable to use three monochromatic lights, in practice the colour filters used were determined by the sensitivity of the photomultiplier and the power of the light source, the latter being restricted by the design and optical arrangement of the ophthalmoscope. Therefore the selection of suitable filters had to be a compromise between theoretical and practical requirements which precluded the use of highly selective filters. The filters were:

Red (Ilford Spectrum Red No. 608).

Cyan (blue-green) (Ilford Cyan No. 307).

Yellow-green (Ilford Bright Spectrum Yellow-green No. 625).

Orange (Ilford Spectrum Orange No. 607).

\section{Electronic System}

Since light is the basic form of energy used in this instrument and the information is to be displayed in graphical form, transformation from light to electrical energy is necessary. Also, since the light used is pulsed, successive pulses representing different parts of the light-spectrum, it is essential to differentiate between these pulses and to present them as separate tracings on a recorder. It is the purpose of the electronic section of the instrument to perform these two functions. The way in which this is achieved is now to be described with reference to the block diagram (Fig. 2).

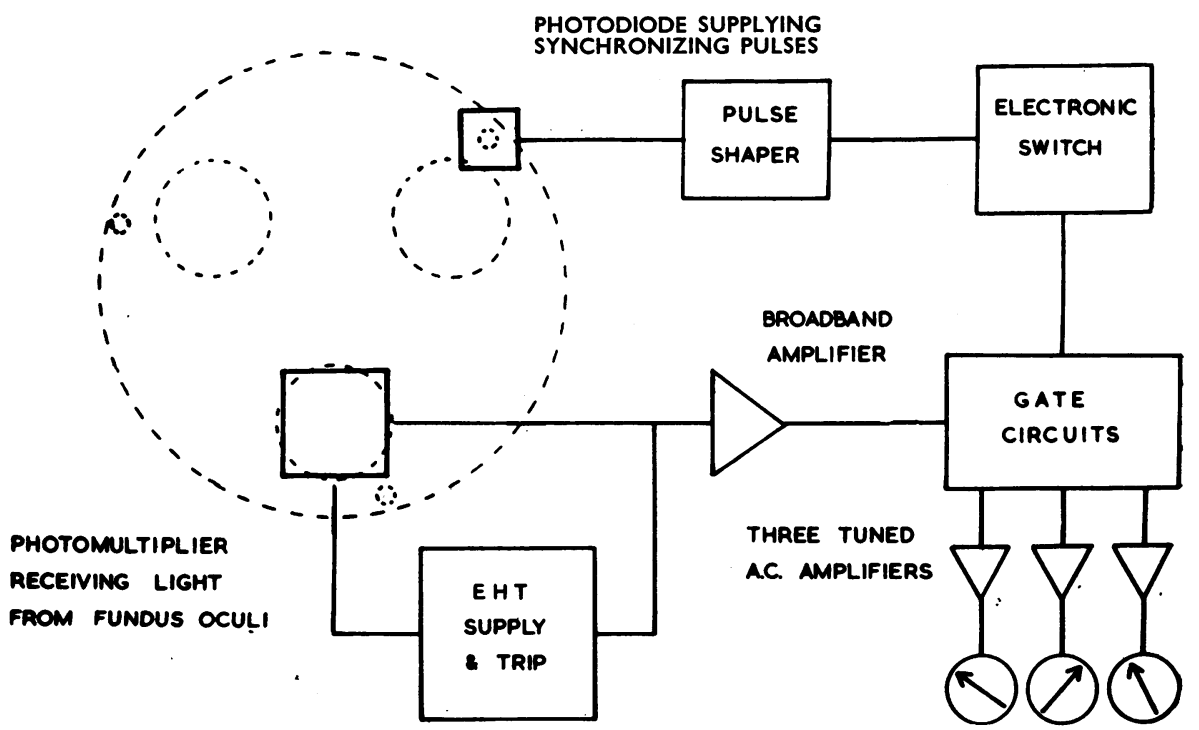

METERS AND RECORDING APPARATUS

FIG. 2.-Block diagram of electronic section of apparatus. 
As already described, steady light is "chopped" into pulses by means of a rotating disc before it enters the optical section of the instrument. This disc, driven by a D.C. motor at a constant speed of 2,500 r.p.m., contains the three colour filters mounted over circular holes. Hence pulses of light at a frequency of 125 per second, representing successively three bands in the colour spectrum are projected into the eye and reflected back from the fundus on to a sensitive photomultiplier tube (EMI 9528B). An E.H.T. stabilized power-supply energizes the photomultiplier to a potential of up to 1,000 volts. This supply also contains a "safety-trip", which protects the photomultiplier by removing the high voltage in the event of too much light entering the tube.

As the information relating to the amount of light reflected back for each colour is obtained from a single photomultiplier, it is essential that this information be separated into three discrete channels if each channel is to represent a different colour. Furthermore, since the frequency of the pulses is high, this separation is done by means of an electronic switch and gate circuits. Approximately forty samples of the light-levels for each colour are taken every second and these samples are integrated with respect to time in order to produce three separate tracings on paper moving through a recorder at a steady rate.

Before entering the gate circuits the very small signals from the photomultiplier are amplified up to a higher level by means of a broad-band amplifier. The switch consists of two parts. The "Gate Circuits" allow the photomultiplier output to pass into the appropriate channel at the correct instant of time on receipt of a command signal from the "Electronic Switch". That is, supposing Channel 1 represents red, then the photomultiplier output is connected through to Channel 1 only when the hole containing the red filter in the rotating disc is opposite the lamp. As each of the other two colour filters appears in front of the lamp, the "Gate Circuits" connect the photomultiplier to the respective output-channels.

The command signals from the "Electronic Switch" open each gate for just long enough, and at the correct time, so that two channels cannot be connected to the photomultiplier simultaneously. In order to achieve this, the gate-circuits are triggered at the correct instants by electrical pulses arising from the photosensitive diode; the latter is actuated by light "chopped" into pulses by the small apertures near the periphery of the rotating disc, the source being a $12 \mathrm{v}$. lamp supplied by the second Servomex voltage stabilizer. It is then only necessary to set the "Electronic Switch" and position of the disc correctly before starting the disc rotating, in order to ensure that the "Electronic Switch" will always operate the "Gate Circuits" at the correct time.

To prevent the system responding to ambient light, each of the three channels incorporates a tuned amplifier. Each amplifier, being tuned to a frequency of approximately 40 cycles per second (the pulse frequency in each channel), will reject other frequencies, especially those above 40 c.p.s. generated by mainsoperated room-lights, and thus it is possible to operate the equipment in the presence of a small amount of stray light as, for example, from a reading lamp placed above the recorder. A second function of these amplifiers is to bring the signals in each channel up to levels where they will operate the recorder and at the same time display the outputs on three moving coil microammeters.

Provision was made for four ranges of amplifier gain between the photomultiplier and the "Gate Circuits" in order to allow for variations in the amounts 
of light returning from eyes with differing degrees of pigmentation. Since these four ranges were not absolutely linear, it was essential to calibrate the display galvanometers in terms of output of the photomultiplier by feeding simulated photomultiplier outputs at known levels into the broad-band amplifier. The apparatus incorporated an oscillator which was used at the end of each experiment to obtain a series of standard deflections which were recorded on each tracing. By means of this standard and the calibration referred to above, it was possible to convert changes observable on the tracings to alterations in photomultiplier output, which, as already mentioned, are proportional to changes in the amount of light reaching the photomultiplier.

A detailed account of the electronic apparatus just referred to is to be published elsewhere by one of us (K. D. B.).

\section{Procedure}

(A) EXPERIMENTS IN VITRO.-A Ryland's schematic eye was set up with a perspex cell in place of the sliding retinal segment (Fig. 3). A depth of $6.5 \mathrm{~mm}$. was chosen for the cell because this gave a light-path of $13 \mathrm{~mm}$., and with the cell containing a 1/100 dilution of blood it was considered that this would be approximately comparable with a choroidal

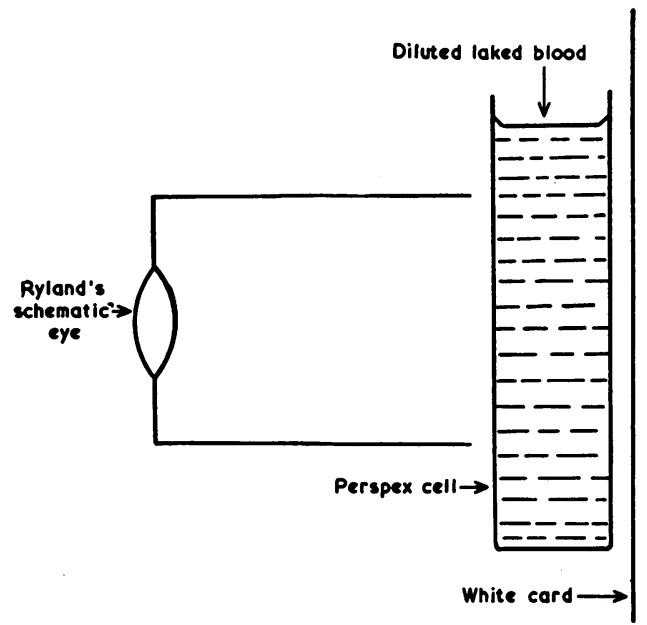

FIG. 3.-Diagram of model used in experiments in vitro. thickness of $0.05 \mathrm{~mm}$. to $0.25 \mathrm{~mm}$. Whole human blood was diluted to $1 / 100$ with water and laked, and $17 \mathrm{ml}$. of this solution were placed in the cell. The ophthalmoscope was set up in the "viewing" position in front of the "schematic" eye, and the outputs obtained with red, cyan, and yellow-green filters in the rotating disc were recorded. $2 \mathrm{ml}$. water were added to the solution of blood in the cell and stirred for a short time; the new outputs were recorded. Successive additions of the same amounts of water were made at intervals.

For studying the oxygenation and deoxygenation of blood, two procedures were followed. In the first procedure a $1 / 100$ dilution of laked blood was placed in a conical flask through which a stream of nitrogen was passed, and was shaken gently until the solution appeared to be reduced, this change being confirmed with a hand-spectroscope. This solution was then placed in the perspex cell and the outputs from the photomultiplier recorded as before. Oxygen was then bubbled through the solution in the cell until it 
was oxygenated, the change in the outputs being recorded continuously. In the second procedure an oxygenated solution of laked blood was placed in the cell and nitrogen was bubbled through until the changed outputs became steady. The nitrogen was then replaced by oxygen, the changes in outputs being continuously recorded.

For studying the effect of adding Evans blue to blood, the perspex cell containing $25 \mathrm{ml}$. of a 1/100 dilution of laked blood was set up behind the "schematic" eye, the colour filters being red, cyan, and orange. The recording was begun and additions of $0.01 \mathrm{ml}$. 0.5 per cent. Evans blue solution were made successively at suitable intervals.

(B) EXPERIMENTS ON RABBITS.-The animals were anaesthetized by intravenous injection of a 25 per cent. solution of urethane in a dosage of 1.75 to $2.00 \mathrm{~g} . / \mathrm{kg}$. The trachea was cannulated, and in some experiments the carotid arteries and cervical sympathetic trunks were exposed, and a hypodermic needle connected to a saline reservoir was introduced into the anterior chamber. The eyelids were held apart by suitably placed sutures and the cornea was kept moist by a saline drip. The pupil was dilated with atropine and the animal's head fixed in a holder with the eye directly in front of the ophthalmoscope.

(C) Experiments on Humans.-One pupil was dilated with 2 per cent. homatropine and 2 per cent. cocaine drops, and the upper eyelid was blackened with burnt cork so that the light reflected from it during blinking was reduced to a minimum. The subject was seated in a comfortable position, with his head firmly supported in front of the ophthalmoscope by means of a foreheadrest and a biting-board with an attached dental mould. The position of the eye to be examined was set by adjusting a fixation-light viewed by the other eye.

The intra-ocular pressure was raised by the application of a Bailliart's ophthalmodynamometer directly to the globe on the temporal side in the region of the equator. The movement of the eye caused by this procedure was compensated by an adjustment of the ophthalmoscope.

In order to change the oxygenation of the blood, the subject was instructed to breathe deeply for about $30 \mathrm{sec}$. and then to hold his breath in expiration for as long as possible. In some experiments an additional record was also made from a Stanco oximeter which registers the change in oxygenation of the blood in the tissues of the ear.

(D) GENERAL:- In all experiments care was taken to ensure that the incident beam of light entered the eye in the correct position, i.e. through the lower half of the dilated pupil. The voltage applied to the photomultiplier and the gain of the amplifiers were adjusted to bring the output into a range suitable for recording. Wherever possible the outputs obtained with the three colours were roughly equalized by placing neutral density filters in the appropriate large apertures in the rotating disc. 
A Lumicord multichannel apparatus (Cinetronics Ltd.) was used to record the amplified outputs of the photomultiplier. It had been shown experimentally that, within the range of illumination employed, the output of the photomultiplier was proportional to the amount of light falling thereon, and by the use of the calibration referred to above any galvanometer deflection could be expressed as an output of the photomultiplier, thereby giving a direct measure of the amount of light returning from the fundus oculi. The terms "red output", "green output", etc., will refer to the outputs of the photomultiplier in response to the amounts of red or green light respectively returning from the eye. Thus, a rise in the red output means an increase in the amount of light reaching the photomultiplier from the eye implying a decrease in absorption of red light by the fundus oculi. Every record shows three tracings. The upper tracing always shows the red output from the eye, and the middle tracing shows a yellow-green or cyan output. The lower tracing usually gives a second green output, but in experiments using Evans blue it shows the orange output from the eye; in three experiments the lower tracing was not obtained from the eye but was used to register changes from the ear oximeter. An increase in output of the photomultiplier is indicated by a downward movement of the tracing, as can be seen from the output calibrations (in microampères $\mu \mathrm{A}$.) on each figure. The vertical lines in all but one of the figures represent intervals of one minute. In the preparation of these illustrations for publication it was necessary to intensify some of the original tracings with Indian ink.

\section{Results}

\section{(A) EXPERIMENTS IN VITRO}

(i) Changes in concentration of blood.

(ii) Changes in oxygenation of blood.

(iii) Addition of Evans blue to blood.

(B) EXPERIMENTS IN VIVO

(i) Changes in the amount of blood in the choroid.

(a) Occlusion of the carotid artery in rabbits.

(b) Lethal injection of Nembutal in rabbits.

(c) Cervical sympathetic stimulation in rabbits.

(d) Inhalation of amyl nitrite in rabbits.

(e) Changes in intra-ocular pressure in the rabbit.

(f) Changes in intra-ocular pressure in human subjects.

(ii) Changes in the colour of choroidal blood.

(a) Intravenous injection of physiological saline in rabbits.

(b) Intravenous injection of Evans blue in rabbits.

(c) Change in oxygen saturation during apnoea after deep breathing in human subjects. 
(A) EXPERIMENTS IN VITRO

(i) Changes in Concentration of Blood.-Fig. 4 shows the record obtained from such an experiment and the graph (Fig. 5, opposite) derived from this tracing shows the outputs of the photomultiplier. It is clear that, whilst an almost two-fold change in the concentration of blood had no effect on the red output, the outputs for both cyan and yellow-green fell with each increase in concentration.

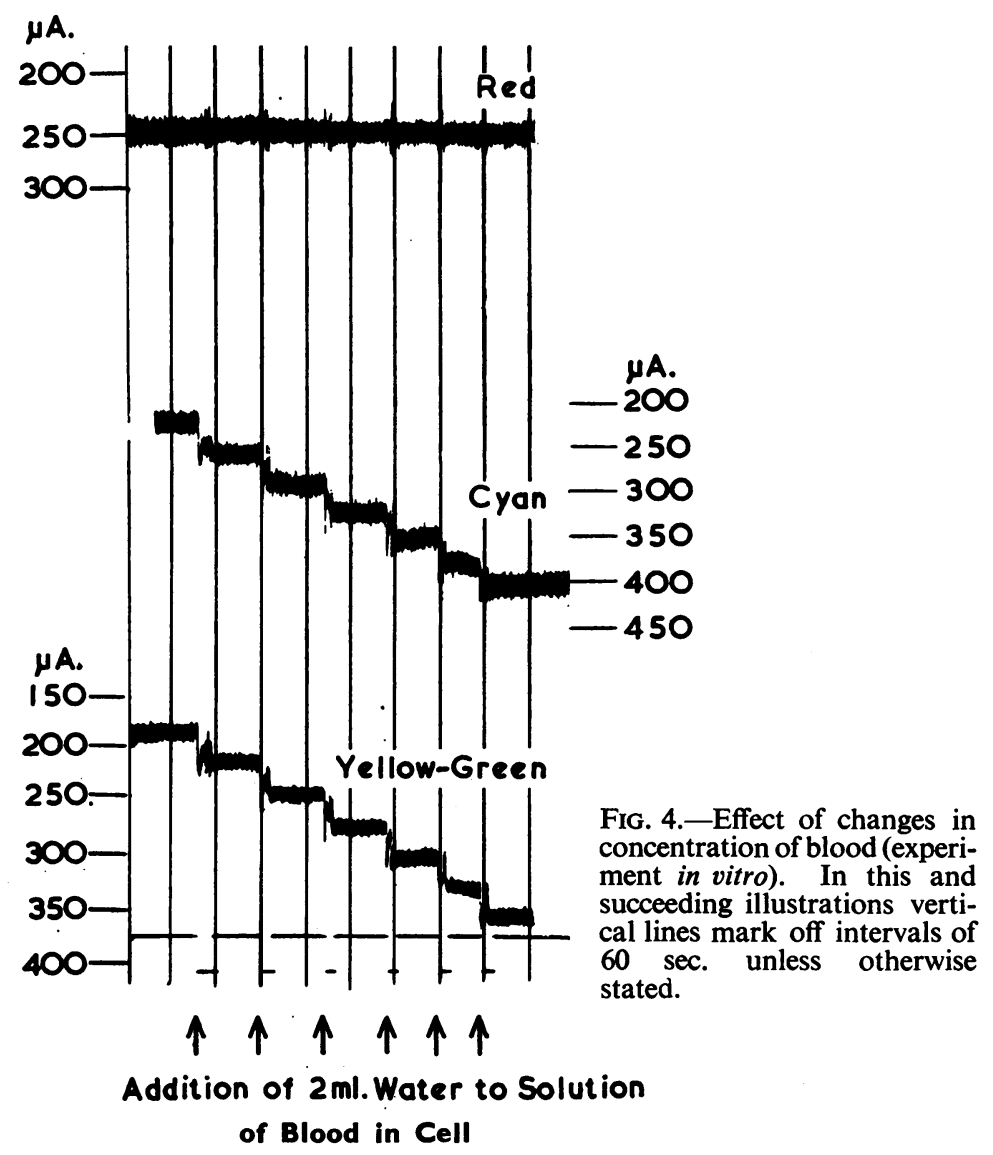

(ii) Changes in Oxygenation of Blood.-Fig. 6 (opposite) shows the record obtained when the oxygenation of the solution of blood was changed by the second of the two procedures described above. It will be noted that, whilst the yellow-green output showed no change, the outputs for red and cyan changed with alterations in oxygenation. As nitrogen was bubbled through the solution the red output fell slowly, and it rose rapidly to its original level when the solution was re-oxygenated. By contrast, the cyan output fell when the solution was exposed to nitrogen and rose again on re-oxygenation. 


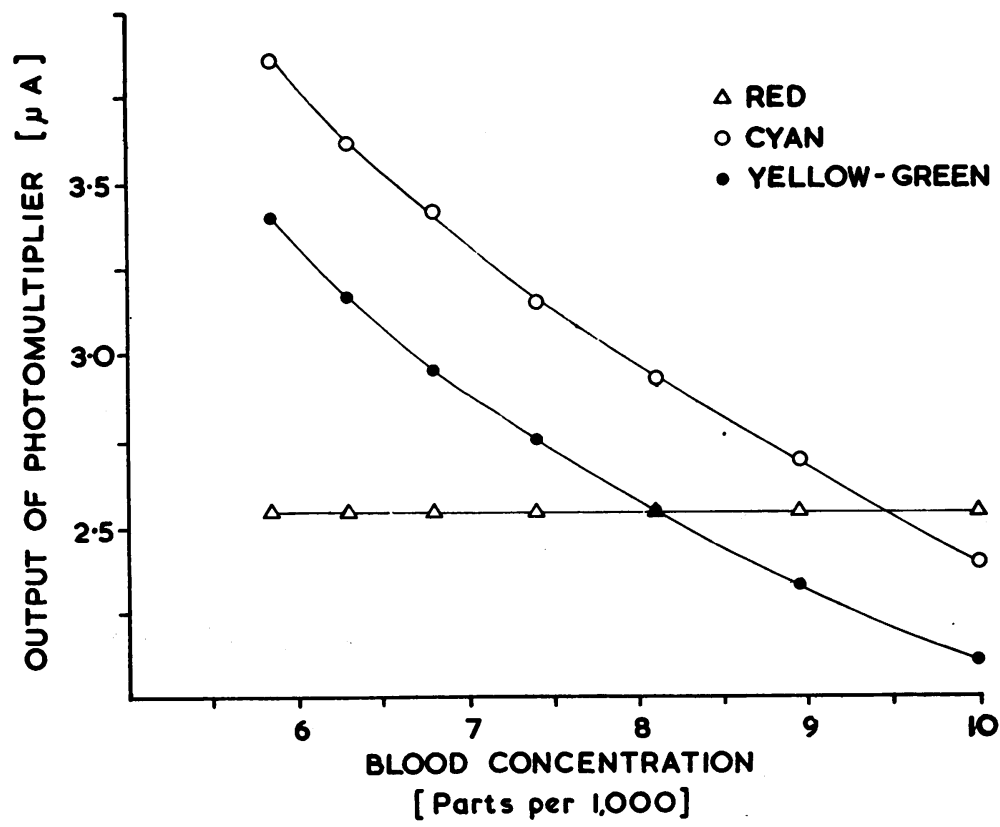

FIG. 5.-Results of Fig. 4 expressed in terms of outputs of the photomultiplier.

In the two instances in Fig. 6, when the blood was changed from the reduced to the oxygenated condition the red output rose by about 11 per cent. and the cyan fell by about 5 per cent.

Fig. 6.-Effect of changes in oxygenation of blood (in vitro experiment).

$\mathrm{O}_{2}$ bubbled through reduced solution of blood.

$\mathrm{N}_{2}$ bubbled through blood.

$\mathrm{O}_{2}$ bubbled through blood.

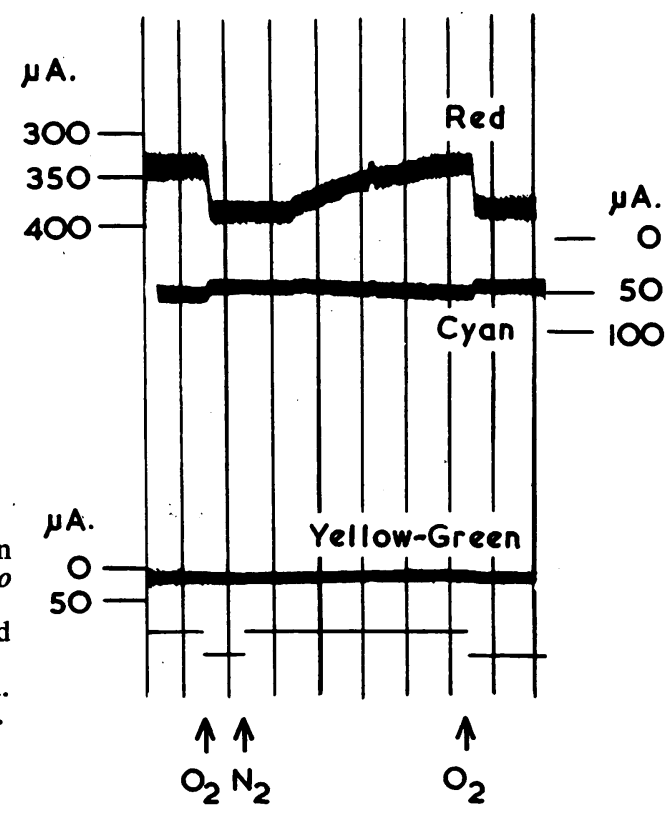


(iii) Addition of Evans Blue to Blood.-Fig. 7 shows the record obtained in such an experiment. The changes in the output of each colour with alteration in the concentration of Evans blue are represented graphically in Fig. 8 (opposite), which shows that, whilst all three outputs fell with increasing concentration of Evans blue, this effect was most marked for the orange output.

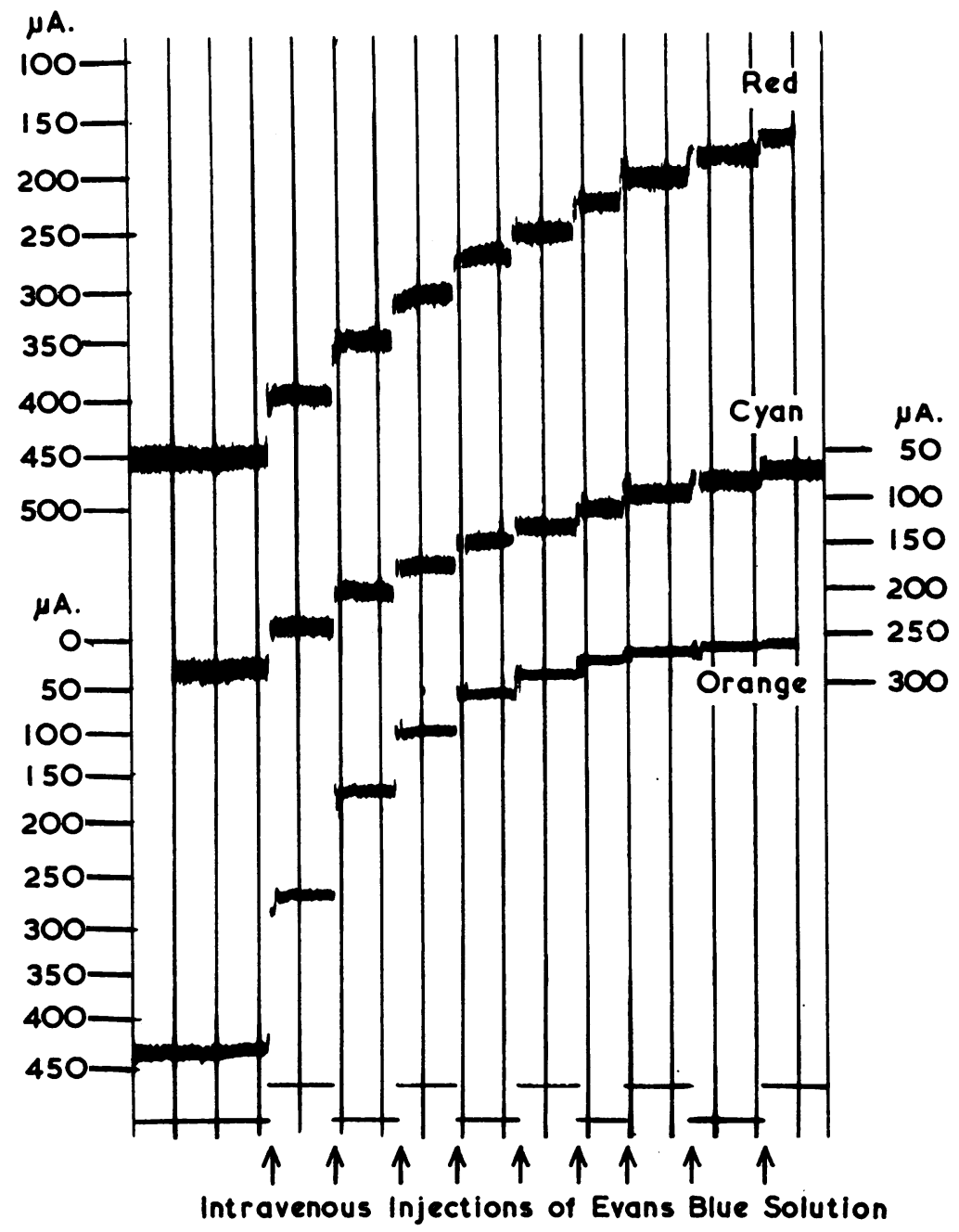

Fig. 7.-Effect of intravenous injections of Evans blue solution in rabbit.

(B) EXPERIMENTS IN VIVO

(i) Changes in Amount of Blood in the Choroid

(a) Carotid Occlusion.-Fig. 9 (opposite) shows the recording from the left eye during the occlusion of the left common carotid artery in an albino 


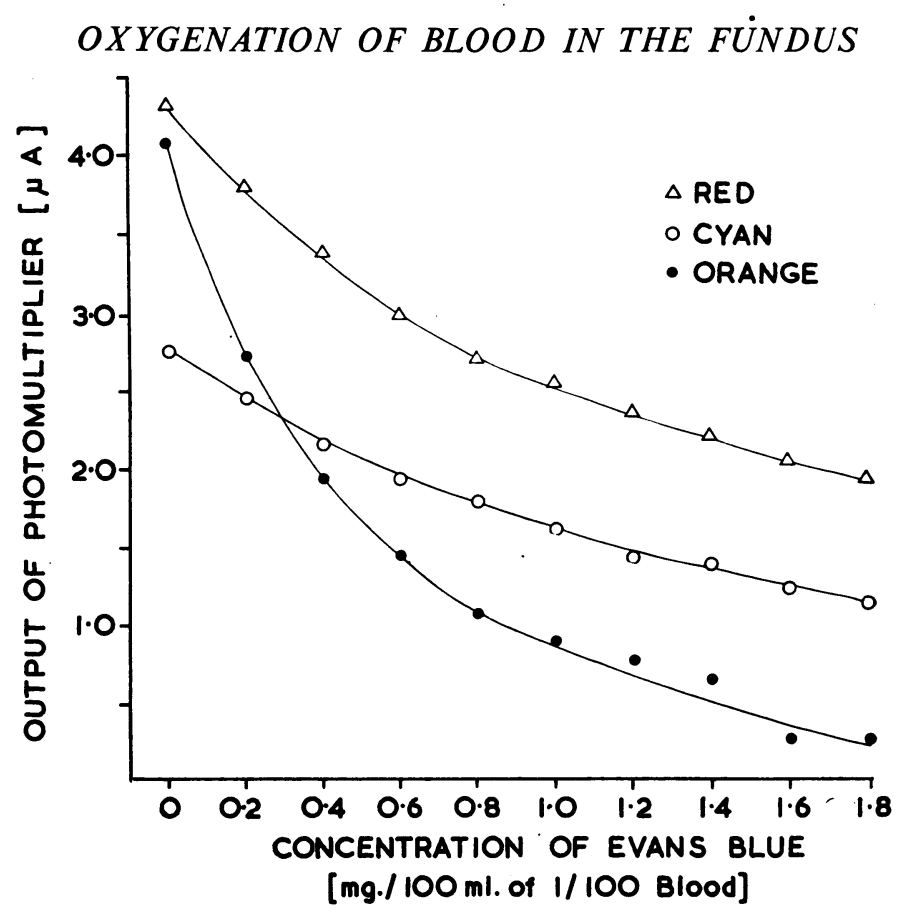

171

Fig. 8.-Results of Fig. 7 expressed in terms of outputs of the photomultiplier.

rabbit. During the period of carotid occlusion there were definite rises in the yellow-green output and in the cyan output, these changes occurring rapidly and synchronously with the onset and cessation of carotid occlusion. The red output by comparison showed little change.

FIG. 9.-Effect of carotid occlusion in a rabbit.

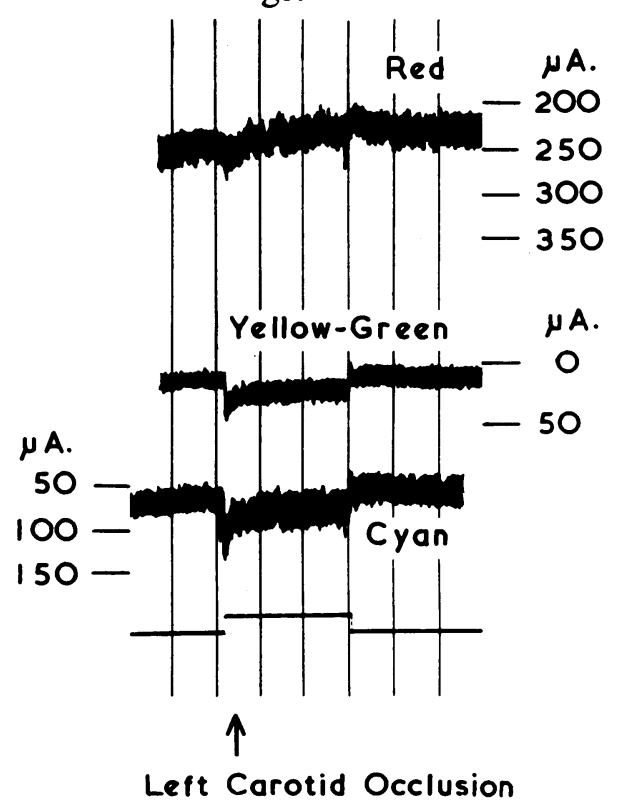


(b) Intravenous Nembutal.-Fig. 10 shows the recording from the eye of a pigmented rabbit during the intravenous injection of a lethal dose of Nembutal. An increase was noted in all three outputs, but this was proportionately greater for the yellow-green and cyan than for the red.

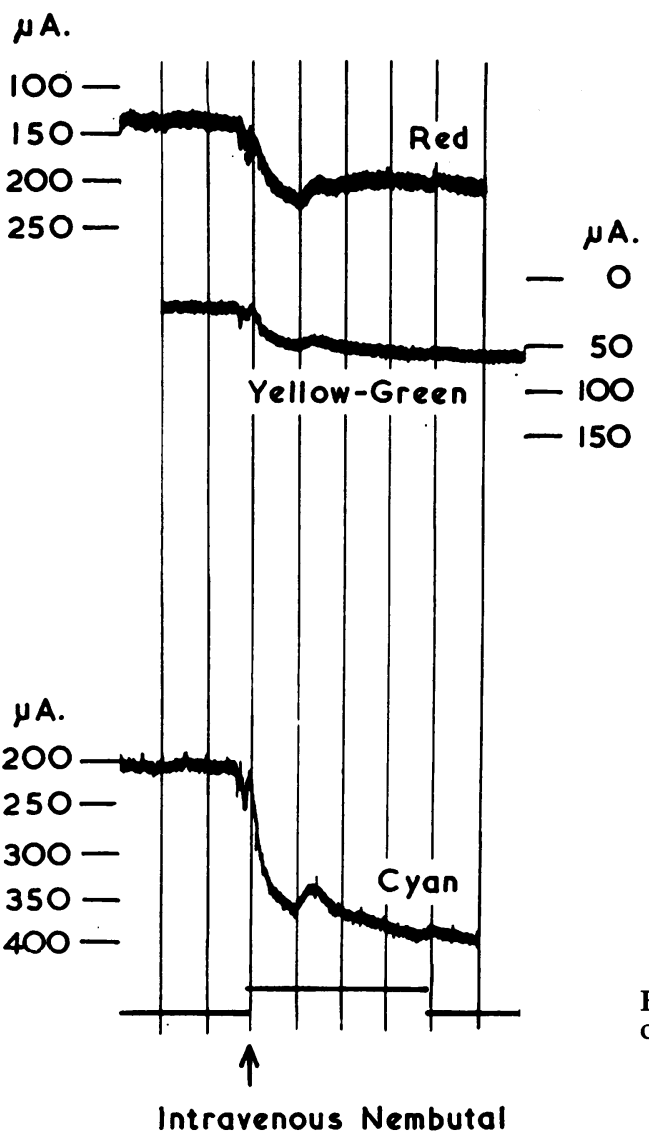

Fig. 10.-Effect of lethal dose of Nembutal in a rabbit.

(c) Cervical Sympathetic Stimulation.-The pre-ganglionic part of the left cervical sympathetic trunk in an albino rabbit was stimulated electrically (Fig. 11, opposite). A rise in output occurred for all three colours, especially for yellow-green and cyan. The changes commenced almost synchronously with the onset of stimulation and persisted through the period of stimulation. On cessation of the stimulus, all three outputs returned gradually towards their initial levels. In the experiment illustrated, the red output increased by about 25 per cent. of its initial value, whereas the output for yellow-green increased about eight times, and for cyan about five times.

(d) Amyl Nitrite.-In an albino rabbit the inhalation of amyl nitrite caused the outputs for all three colours to fall, but the changes in cyan and yellow-green were much greater than the change in red (Fig. 12, opposite). 
Fig. 11.-Effect of stimulation of

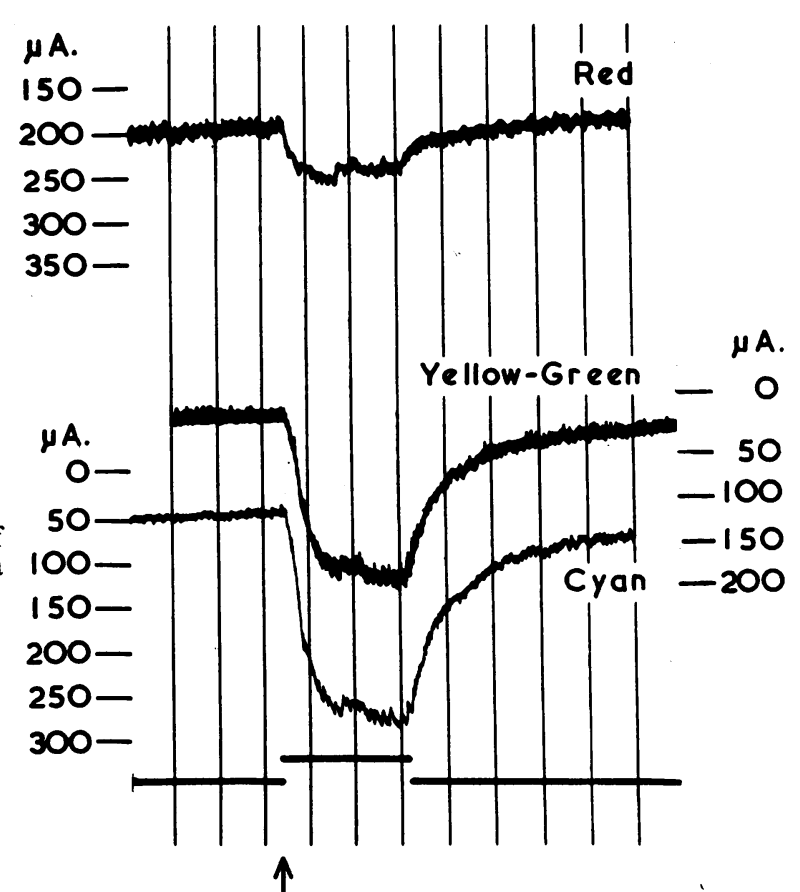
cervical sympathetic nerve in a rabbit.

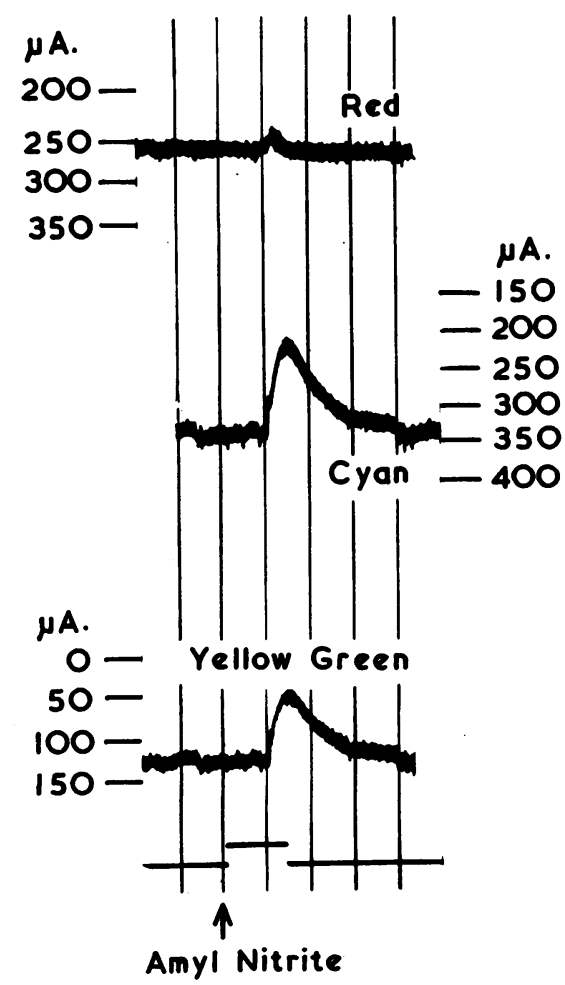

Cervical Sympathetic Stimulation

FIG. 12.-Effect of inhalation of amyl nitrite in a rabbit. 
(e) Changes in Intra-ocular Pressure: Rabbit Eye.-The pressure within the eye was changed artificially by means of an adjustable reservoir containing saline connected to a needle inserted into the anterior chamber. Figs 13 and 14 are records from two albino rabbits.

In Fig. 13 the intra-ocular pressure was raised from 20 to $95 \mathrm{~mm}$. $\mathrm{Hg}$ for $6 \mathrm{~min}$. The cyan and the yellow-green outputs were markedly and persistently increased while the pressure was raised; when it returned to its initial level, both outputs fell rapidly below their original level, falling even lower during the following $15 \mathrm{sec}$. or so, and returning gradually to the original level in 3 to $4 \mathrm{~min}$. The red output on the other hand showed a slight fall during the period of raised pressure, and there was a gradual return to the initial level when the original pressure was restored.

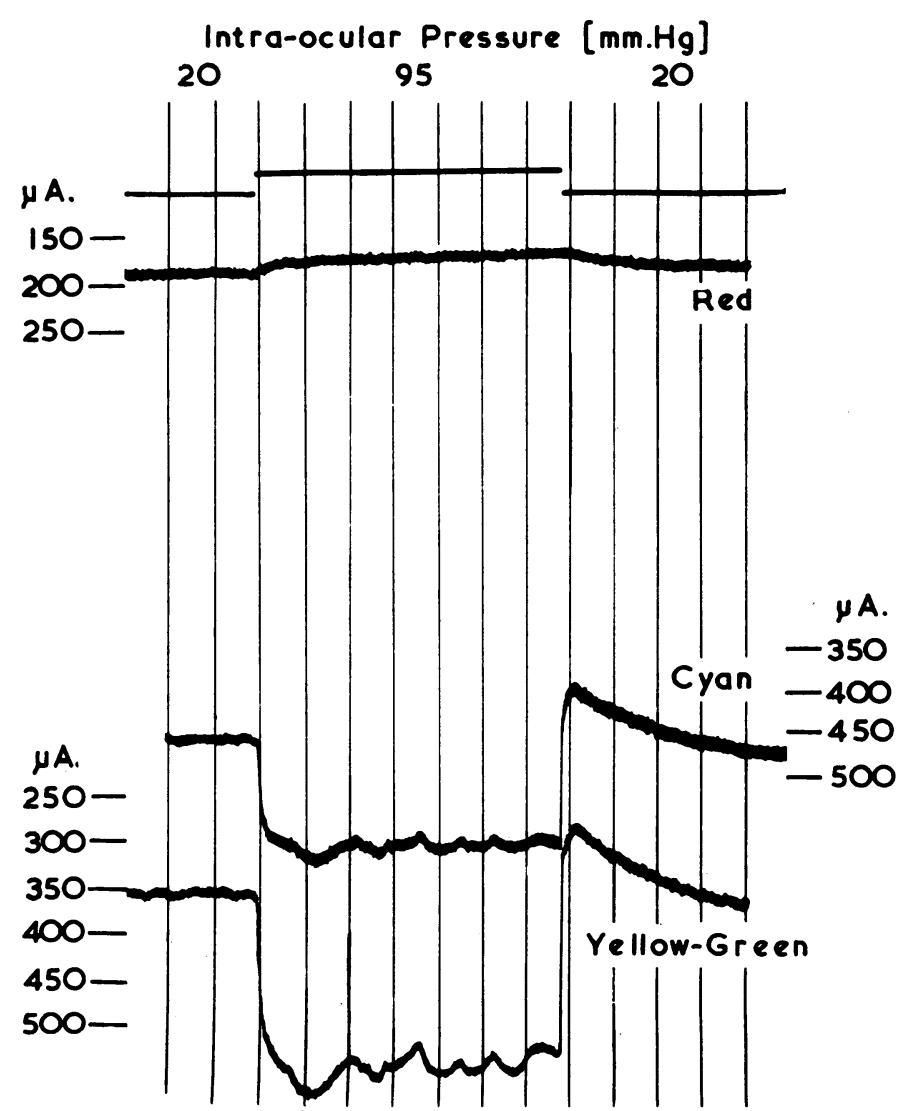

FIG. 13.-Effect of changes in intra-ocular pressure in a rabbit. 
In Fig. 14 the pressure was reduced from 20 to $10 \mathrm{~mm}$. $\mathrm{Hg}$, and throughout this period the cyan and yellow-green outputs were lower and the red output was slightly higher. All three outputs returned rapidly to their original levels when the pressure was restored to $20 \mathrm{~mm}$. Hg.

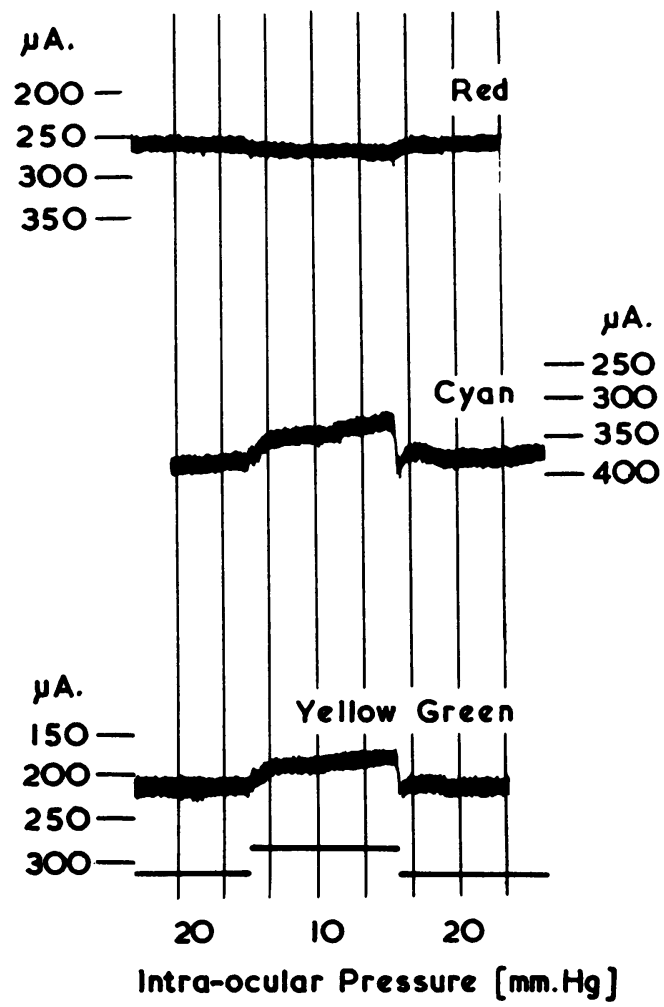

Fig. 14.-Effect of changes in intra-ocular pressure in a rabbit.

( $f$ ) Changes in Intra-ocular Pressure: Human Eye.-Figs 15, 16, and 17 (overleaf) are recordings from a human eye in which the pressure was elevated by applying a Bailliart's ophthalmodynamometer to the lateral aspect of the globe. This caused the eye to be displaced medially, with consequent gross changes in all outputs. An attempt was made to minimize these effects by moving the ophthalmoscope through the same distance medially so that light entered and left the pupil in the same positions as before. A compensatory adjustment of the ophthalmoscope was also made in the other direction when the dynamometer was removed.

At the moment of application of the dynamometer, there was a large fall in the red output and rises in the two green outputs, which were due to the displacement of the eye. After adjustment of the position of the ophthalmoscope, the red output rose to its initial level but the yellow-green and cyan outputs were both increased and remained so until the dynamometer was 


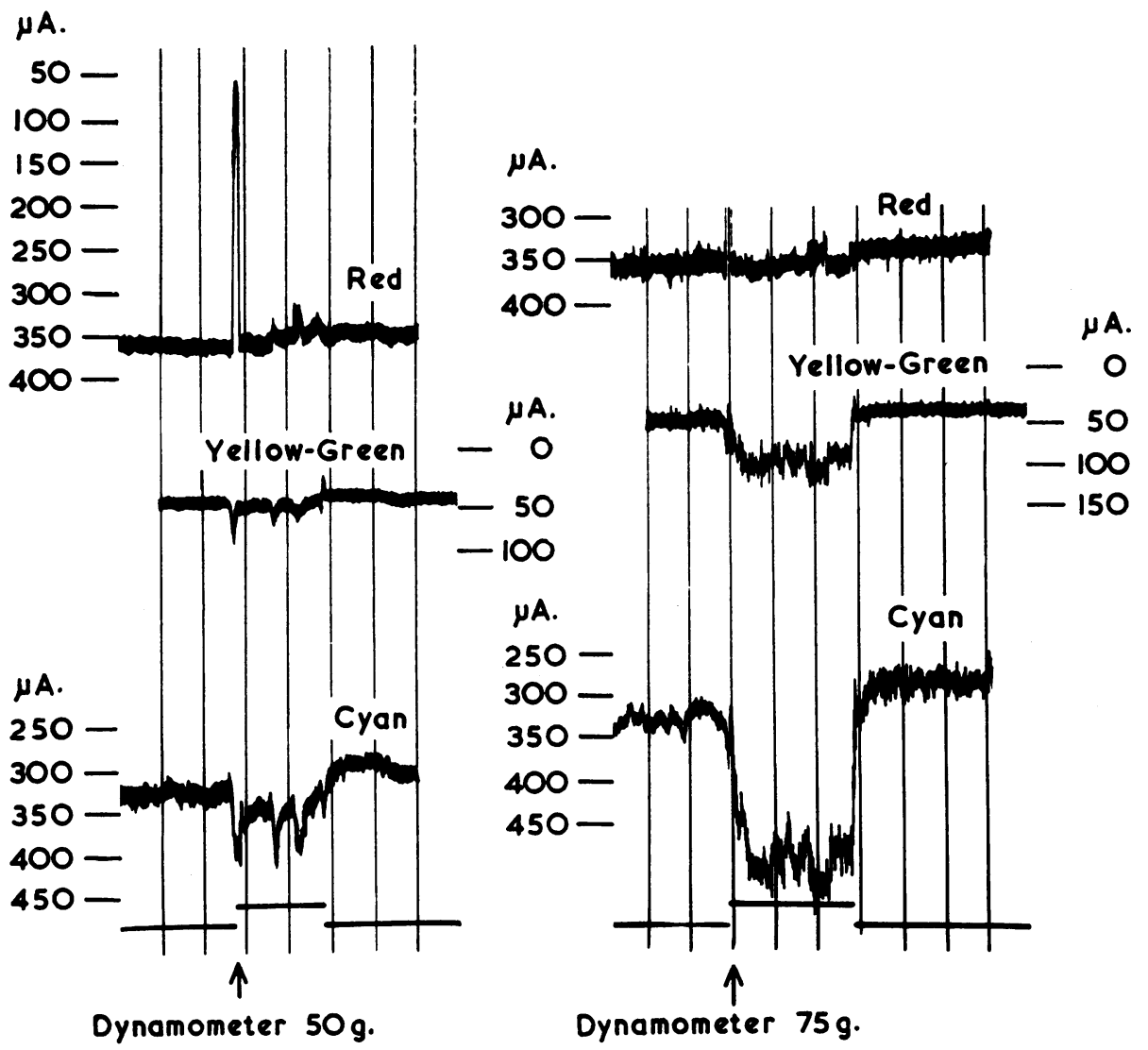

FIGs 15 and 16.-Effects of changes in intra-ocular pressure in the human eye (Dynamometer 50 and $75 \mathrm{~g}$.$) .$

removed. These effects were greater when a larger force was applied by the dynamometer. The results of one such experiment are summarized in Table I, which shows that the red output sometimes increased and sometimes decreased, but that the changes never exceeded 5 per cent. On the other

TABLE I

RESULTS OF APPLICATION OF DYNAMOMETER TO HUMAN EYE

\begin{tabular}{c|c|c|c}
\hline $\begin{array}{c}\text { Force from } \\
\text { Dynamometer } \\
(\mathrm{g})\end{array}$ & \multicolumn{3}{|c}{$\begin{array}{c}\text { Changes in Output during Application of Dynamometer } \\
\text { (expressed as Percentage of Initial Level) }\end{array}$} \\
\cline { 2 - 4 } & Red & Yellow-Green & Cyan \\
\hline 25 & -3 & 0 & 0 \\
\hline 50 & +3 & 0 & +5 \\
\hline 75 & -1 & +31 & +35 \\
\hline 100 & +5 & +62 & +68 \\
\hline
\end{tabular}




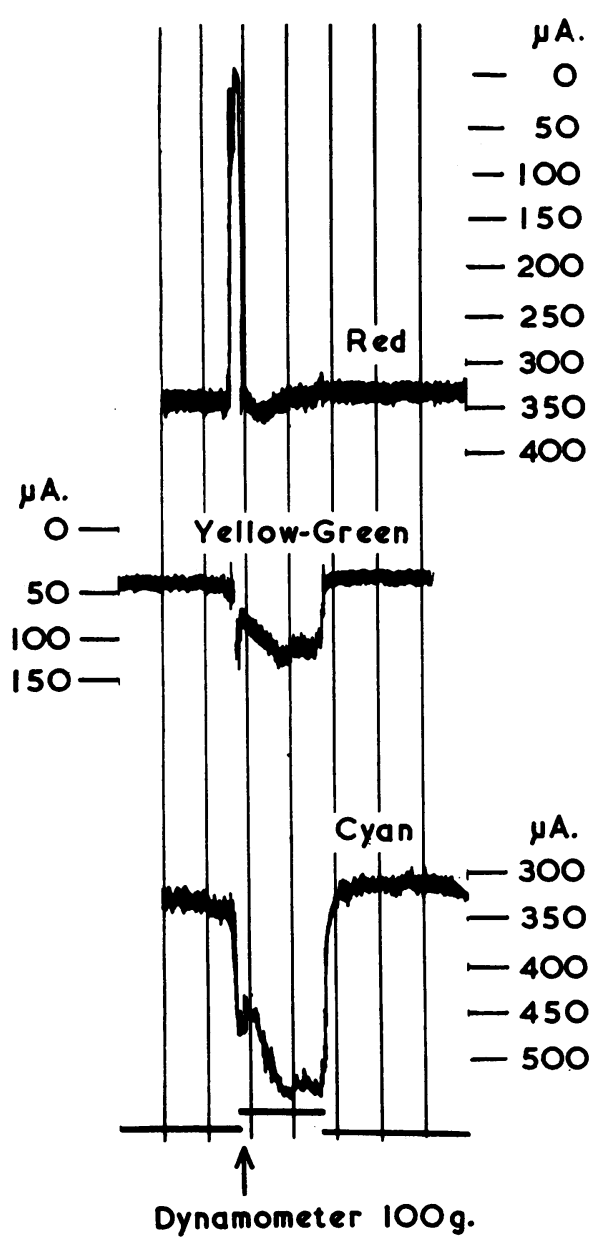

FIG. 17.-Effect of change in intra-ocular pressure in the human eye (Dynamometer $100 \mathrm{~g}$.). hand, where any change occurred in the yellow-green or cyan outputs, this change was always a rise which became more marked the greater the force applied by the dynamometer.

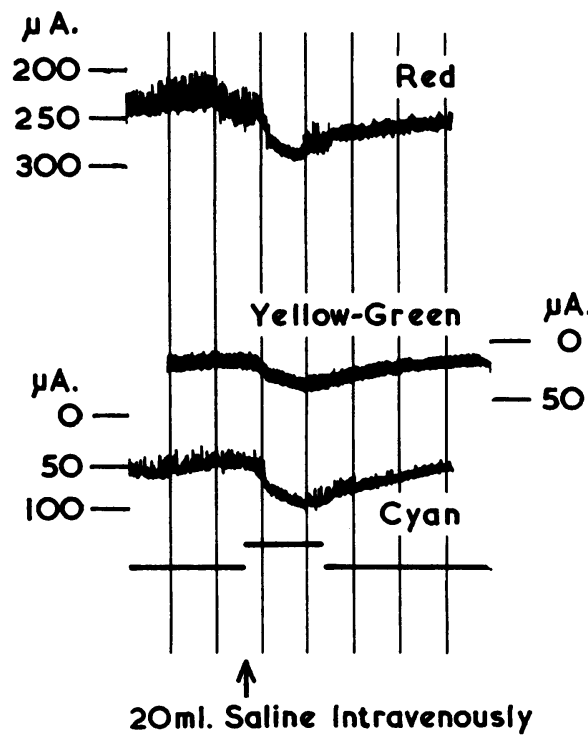

FIG. 18.-Effect of intravenous injection of saline in a rabbit.

\section{(ii) Changes in Colour of the Choroidal Blood}

(a) Injection of Saline: Rabbits.-Fig. 18 shows the effect of injecting $20 \mathrm{ml}$. physiological saline into the ear-vein of a rabbit. The red output rose by 15 per cent., and the yellow-green and cyan outputs by approximately 100 per cent.

(b) Injection of Evans Blue.-A series of injections of Evans blue was made into the ear-vein of a rabbit (Fig. 19, overleaf). In this experiment the colour-filters used were red, cyan, and orange. With each injection of dye the output for cyan fell temporarily, but this output showed no persistent change. By contrast the outputs of red and orange showed persistent falls with each 
successive injection of dye. Table II (below) summarizes these persistent changes and shows clearly that the orange filter gave the maximum effect.

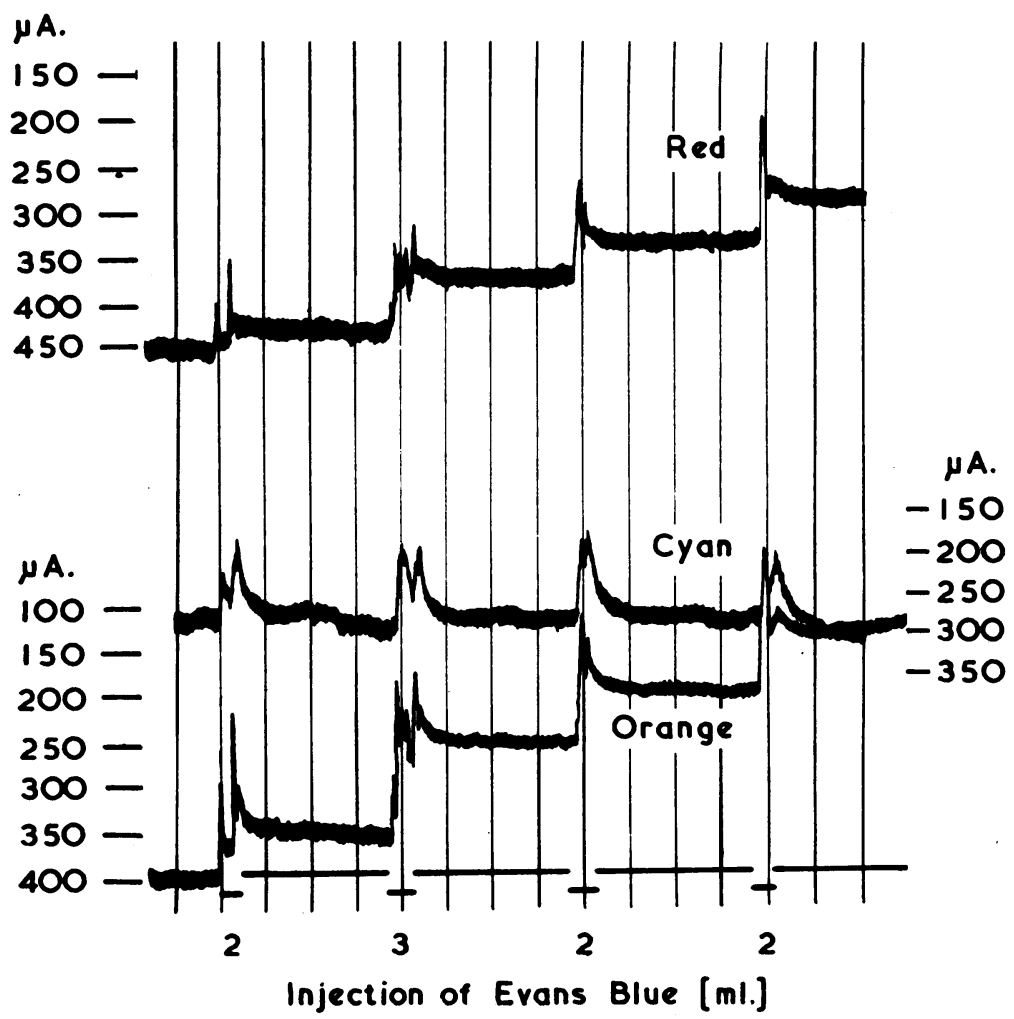

FIG. 19.-Effect of intravenous injection of Evans blue solution in a rabbit.

TABLE II

CHANGES IN OUTPUT AFTER INJECTION OF EVANS BLUE

\begin{tabular}{c|c|c|c}
\hline $\begin{array}{c}\text { Total Volume 1 per } \\
\text { cent. Evans Blue } \\
\text { Injected } \\
\text { (ml.) }\end{array}$ & \multicolumn{3}{|c}{ Changes in Output (expressed as Percentage of Initial Level) } \\
\cline { 2 - 4 } & Red & Cyan & Orange \\
\hline 0 & 100 & 100 & 100 \\
\hline 2 & 97 & 99 & 93 \\
\hline 5 & 89 & 99 & 75 \\
\hline 7 & 84 & 99 & 66 \\
\hline 9 & 76 & 100 & 53 \\
\hline
\end{tabular}

(c) Changes in Oxygen Saturation: Human Subjects.-Figs 20 to 22 are recordings taken from the eye using two-colour filters only, the third channel 


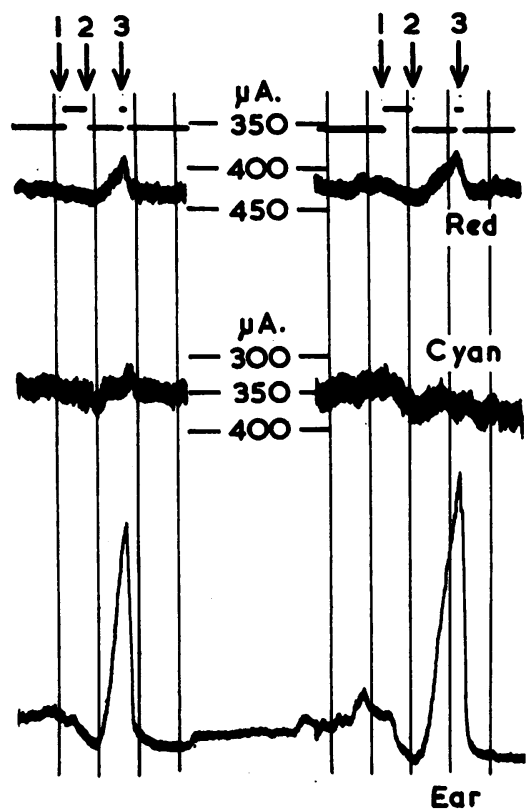

Fig. 20.-Effect of apnoea after deep breathing in a human subject (D.P.G.).

60 sec.

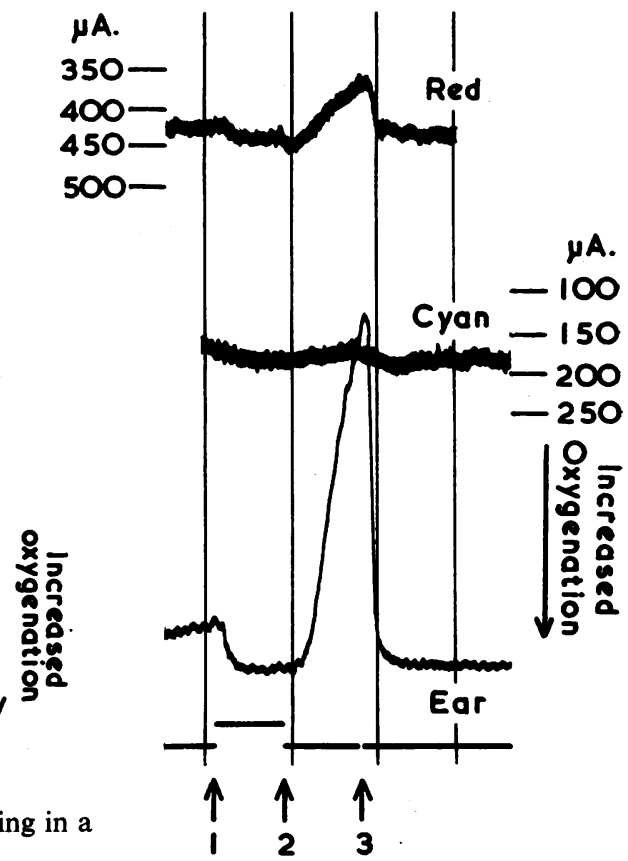

FIG. 21.-Effect of apnoea after deep breathing in a human subject (A.L.)

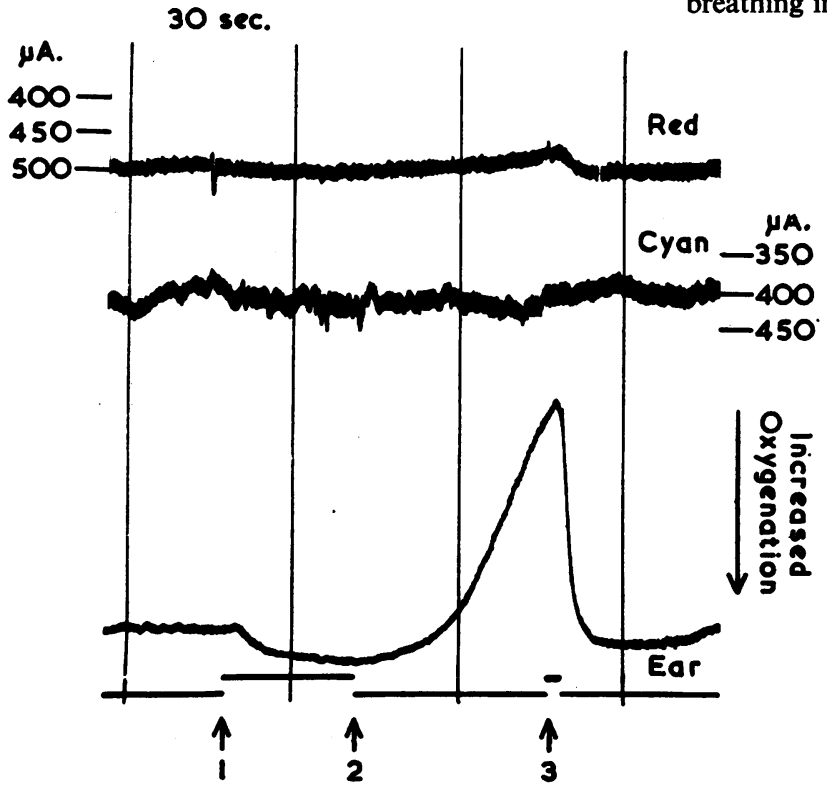

In Figs 20-22

I. Deep Breathing

2. Apnoea

3. End of Apnoea

Fig. 22.-Effect of apnoea after deep breathing in a human subject (J.G.).

Vertical lines in this figure mark off intervals of $30 \mathrm{sec}$. 
of the recorder being connected to a conventional ear-oximeter. The tracings show the changes which occurred during apnoea following a short period of deep breathing. During deep breathing the lower tracing shows a small increase in oxygen saturation of the blood in the ear and a rapid fall in oxygenation during apnoea. (Although an accurate calibration was not done, this change as read on the instrument was of the order 10-15 per cent.) The middle tracing, which represents the cyan output from the eye, shows no consistent change. During apnoea the red output falls but returns rapidly to its original level when normal breathing is resumed. It should be noted from the tracing that the red output from the eye reached its minimum at the same time as the lowest level of oxygen saturation as indicated by the ear-oximeter. Also the rates of fall and recovery of the red output from the eye, as indicated by the general shape of the curve, correspond closely with the tracing obtained from the ear-oximeter.

\section{Discussion}

It is obvious that there are considerable differences between conditions in the model which was used for the in vitro experiments and those in the living eye. Firstly, in the model laked blood (i.e. blood pigments in homogeneous solution) was used, whereas in the living choroid the blood pigments are contained in corpuscles circulating in vessels surrounded by other tissues both pigmented and non-pigmented. Furthermore, a layer of diluted blood $6.5 \mathrm{~mm}$. thick was used in the model, whereas in the eye the whole blood in the choroid presents a much thinner film. Lastly, the light-scattering and light-absorbing properties of the media and other tissues in the living eye had no parallel in the model. From these considerations it is impossible to expect any exact quantitative relationships between the in vitro and in vivo experiments, but nevertheless it is reasonable to assume that the general trend of changes would be similar. Table III (opposite) summarizes the results and shows that the trends of the responses are in fact similar for each type of procedure whether conducted in vivo or in vitro. There is no absolute agreement between the results of the two types of experiment, but the greatest changes for a particular procedure occurred consistently with the same colour in vitro and in vivo. Further evidence that the responses recorded do in fact reflect changes in the blood in the choroid is forthcoming from a comparison of the record of the red output from the eye with the recording from the ear-oximeter in human subjects during deep breathing and apnoea; these show that during apnoea there is a fall in the red output from the eye which follows the same course in time as the degree of deoxygenation indicated by the ear-oximeter.

The results so far obtained show that the apparatus is capable of detecting changes in the amount and oxygenation of blood in the choroid, and we 
TABLE III

SUMMARY OF RESULTS

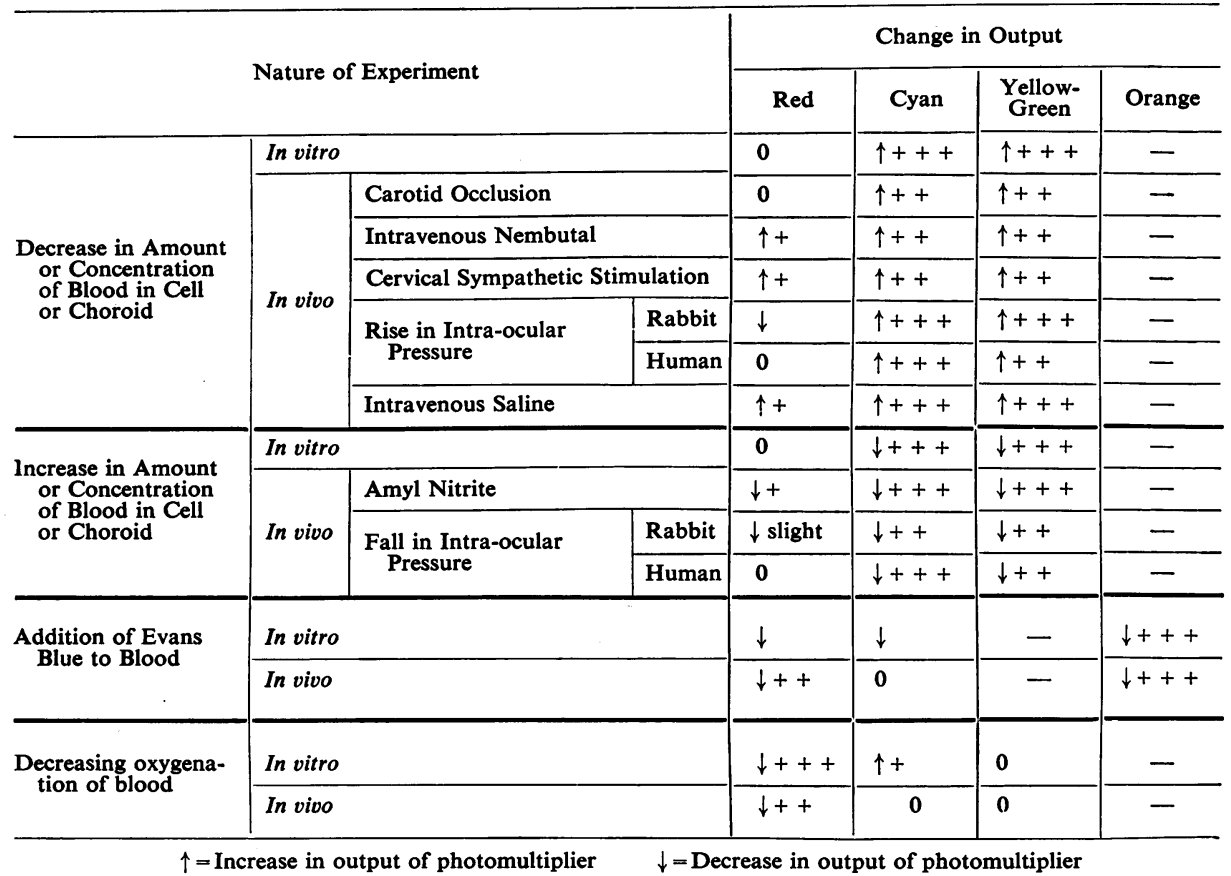

propose to employ this technique to study the effect of changes in intraocular pressure on the choroidal circulation.

\section{Summary}

(1) It is probable that an impairment of the circulation of blood within the eye caused by a rise in intra-ocular pressure is partly responsible for the loss of visual function in glaucoma.

(2) An apparatus was designed to measure photoelectrically the amounts of light of different colours reflected by the fundus oculi. By choosing suitable colours it was possible to assess changes in the thickness of the blood film and in its oxygenation, together with alterations in the concentration of a dye injected into the blood stream.

(3) Experiments were carried out in vitro using a "model" eye in which the concentration and oxygenation of laked blood were varied. Further tests were done adding known amounts of Evans blue solution to blood.

(4) Experiments were carried out in vivo on rabbits in which the amount and colour of blood in the choroid was altered by carotid occlusion, cervical sympathetic stimulation, changes in intra-ocular pressure, intravenous injection of Evans blue, etc. 
(5) Experiments were also done on human subjects in which it was shown that artificially induced changes in intra-ocular pressure resulted in alterations detectable by the apparatus. Furthermore, during a period of apnoea following deep breathing, the apparatus registered changes from the eye which followed the same course in time as the degree of oxygenation indicated by a conventional oximeter placed on the ear.

(6) The results in vitro and in vivo prove that the apparatus responds to changes in the amount and oxygenation of choroidal blood and suggest that it may provide a means of studying the condition of the blood-supply in the posterior segment of the eye.

Part of the expenses of this work was supported by a grant from the Pigott Wernher Trust Fund.

\section{REFERENCES}

Niedermeier, S. (1958). Klin. Mbl. Augenheilk., 132, 828.

Rushton, W. A. H. (1956). J. Physiol. (Lond.), 134, 11.

SCHUBERT, G. (1936). v. Graefes Arch. Ophthal., 135, 558.

Weale, R. A. (1953). J. Physiol. (Lond.), 122, 322.

ZiJLSTRA, W. G. (1958). "A Manual of Reflection Oximetry". Van Gorcum, Assen, Netherlands. 